TURIZAM

Volume 14 , Issue 2

66-77 (2010)

\title{
A Comparison of Tourist Expectations and Satisfaction: A Case Study from Antalya Region of Turkey
}

\author{
Akın Aksu* \\ Ebru Tarcan Iç̧igen* \\ Rüya Ehtiyar* \\ Received: May 2010 | Accepted: June 2010
}

\begin{abstract}
For several years the number of tourists visiting Antalya Region has been increasing. It could be argued that Antalya is comparable with a capital city in terms of tourist numbers. Antalya Region hosted over 9 million tourists in 2008. To sustain demand and increase competition of operators in Antalya, it is necessary to create a powerful brand image. This will require a combination effort from all tourism stakeholders. Consequently, it is important to define the current tourist profile visiting Antalya Region, evaluate tourists' expectations and satisfaction, and identify future tourism related research. These outcomes are all important in developing regional tourism. The aim of this study is comparison of expectation-levels and satisfaction-levels of a selected sample of tourists. The findings culminate from research conducted in Antalya Region from a sample of 10.393 tourists during 2008.
\end{abstract}

Key words: Tourist expectation, tourist satisfaction, Turkey, Antalya

\section{Introduction}

Antalya Region is located in the southern part of Turkey; and it attracts many overseas tourists because of its climate and natural beauty. Tourism destinations can be defined as temporary locations for gaining a travel experience, and which is related to the destination's attractiveness (Leiper, 1979:392). According to another perspective, and related to an individual's travel requirements, tourism destinations can be evaluated as reflections of emotions, beliefs and thoughts in enabling perceived satisfaction (Hu, Ritchie, I993:27). Uysal (I998) evaluates destination attractiveness and sources, as supply factors representing pushing forces,

* Akdeniz University School of Tourism \& Hotel Management, Arapsuyu - Campus, Antalya, Turkey, telephone: oo 9024222745 50, fax: 009024222746 70, ebrutarcan@akdeniz.edu.tr, ehtiyar@akdeniz.edu.tr Corresponding Author: aaksu@akdeniz.edu.tr 
which constitute tourist demand. Naturally, tourists will have expectations from tourism destinations, in terms of attractiveness and sources. These expectations can be increased or decreased, resulting from publicity and marketing efforts of the tourism destination. The net result of such efforts will be a specific holiday destination. Receiving new and relevant information focused on the holiday destination, will help tourists in selecting their destination after due consideration is made of their expectations. Normally, expectations of a destination will affect satisfaction levels. In this study, expectation and satisfaction levels of tourists visiting Antalya Region of Turkey were tested by using a range of variables.

\section{Expectation and Satisfaction of Tourists}

Generally, expectation can be defined as performance of establishment, ideal performance or desired performance (Teas, I994: I34). In terms of the relationship between expectation and satisfaction, expectation can be defined as prior estimations made by customers' while receiving service (Oliver, I98I: 27). In successful destination marketing, due to the effects on tourists' destination selections, consuming of goods and services and having the decision to revisit, expectations of tourists are important to understand (Stevens, I992: 46). It is generally accepted that tourists have expectations after selecting a destination for a holiday and that their satisfaction levels during and after their holiday period are functions of their expectations (Huh et al., 2006: 83; Korzay, Alvarez, 2005: I79; Yoon, Uysal, 2005: 55-68). Understanding their expectations will give important clues in developing destination attractiveness and improving tourist goods and services.

The conceptual studies related to customer satisfaction and service quality can be found in the marketing literature (Cronin, Taylor, I992: 55-68; Oliver, I980: 460-469; Parasuraman et al., I988: I2-37; Abdeldayem and Khanfer, 2007: 303-309). The number of studies investigating aspects of customer satisfaction in tourism, travel, hospitality and recreation is increasing (Kozak, Rimmington, 2000: 260). It is recognized that satisfaction affects destination selection decisions, consumption of goods and services at a destination, and intention to revisit. Related research indicates that satisfaction is a function of expectations and overall performance. After comparing the expectations with perceived performance of the destination, destination satisfaction can be considered (Korzay, Alvarez, 2005: I79). In this context, satisfaction resulting from a destination can be better understood by evaluation and perception of tourists regarding a tourism destination (Kozak et al., 2004: 45). Pizam et al. (I978) argue that in calculating satisfaction from tourism destinations, defining satisfaction levels for every attribute of destinations is required.

\section{Methodology}

\section{Study Objectives}

This research was carried out in order to analyze and observe tourism demand in Antalya Region of Turkey. In addition to this, with this study it is possible to inform tourism stakeholders about a precise tourist profile. 


\section{Questionnaire Design}

In order to measure what tourists thought they will get from Antalya Region, the collection of information was facilitated by use of a questionnaire. The questionnaire was translated into four languages (English, German, French and Russian). In developing the questionnaire, national and international related literatures were taken into consideration. Following the literature review, questionnaire attributes were overviewed by a group of tourism expert academicians and representatives of tourism industry. In order to define tourists' expectation and satisfaction of Antalya Region as a tourism destination, I8 attributes/questions were used in the questionnaire. Respondents in the sample were requested to evaluate their satisfaction with each of the I8 attributes using a 7-point Likert-type scale; ranging from very low expectations (I) to very high expectations (7). Additionally, a single overall satisfaction question was asked to test the respondent's overall satisfaction with the Antalya Region - ranging from extremely dissatisfied (I) to extremely satisfied (7).

\section{Data Collection Procedure}

The research was carried out in Antalya Region (the most important tourism destination in Turkey in terms of tourism trips). The sample consisted of foreign tourists who visited Antalya in July, August, September and October 2008. In defining the sample size, the number of questionnaires was computed in accordance with the proportion of the nationalities for the 2007 period as recorded by Ministry of Culture and Tourism, Turkey. The research was carried out by a group of trained undergraduate students during the tourists' departure. During the research in all gates of Antalya International Airport were used for the questionnaire. Sampled tourists were approached and informed about the aim of the research. A total of IO.393 questionnaires were collected.

\section{Data Analysis}

Data analysis was completed using SPSS (I3.O version) (Statistical Programme for Social Sciences). Data were evaluated by using a range of statistical techniques. Frequencies and percentage scores for nominal variables, including socio-demographic and travel behav-

iour characteristics of sampled tourists, were calculated. Expectation and satisfaction levels were evaluated by calculating their arithmetic means. Cluster analysis was applied to explore expectation and satisfaction levels for selected groups. Correlation analysis compared expectation and satisfaction. The summary analysis depicted an expectation-satisfaction matrix; supported by a detailed explanation as follows.

\section{Findings and Discussions}

\section{Socio-Demographic Characteristics of Tourists}

The socio - demographic characteristics and travel behaviour of the sampled tourists are presented in Table I. Females constitute $60.9 \%$ of the participants; and in total 8I \% of the respondents were aged between I5 and 44 years. 5 I. $8 \%$ of the respondents were married; and more than half of the respondents (54.9\%) reported that they had personal annual income of less than I2.OOO Euro. The dominant education-level of the respondents (52 \%) was of undergraduate level; while approximately 30\% of the respondents had secondary or 
primary education. In terms of occupation, the majority of the respondents were government officials (3I.5 \%) and government workers (30.7 \%). With regard to nationality of respondents, tourists from CIS (Commonwealth of Independent States) dominated the sample, with 47.I O \%, followed by German and Austrian tourists (I4.3\%).

As shown in Table I, the majority of the respondents (84.9\%) visited Antalya as a holiday destination through joining a package tour. With regard to travelling companions, the majority of the respondents (88.3\%) were accompanied by spouse, spouse and children, friends/relatives or other people. Only II.7 \% of the respondents travelled alone. The greater majority of the respondents (8I.7 \%) reported that they preferred an all-inclusive holiday as the form of package tour. Some $59.9 \%$ of the respondents stayed in Antalya between 6-IO days.

Table 1 Socio -Demographic Characteristics and Travel Behaviour Information of Respondents

\begin{tabular}{|c|c|c|}
\hline Variables & $\mathbf{N}$ & $\%$ \\
\hline \multicolumn{3}{|c|}{ Socio-Demographic Characteristics } \\
\hline \multicolumn{3}{|l|}{ Gender } \\
\hline Female & 6211 & 60.9 \\
\hline Male & 3986 & 39.1 \\
\hline \multicolumn{3}{|l|}{ Age } \\
\hline $15-24$ & 3252 & 31.8 \\
\hline $25-34$ & 2798 & $27 \cdot 3$ \\
\hline $35-44$ & 2238 & 21.9 \\
\hline $45-54$ & 1330 & 13.0 \\
\hline $55-64$ & 471 & 4.6 \\
\hline 65 and above & 145 & 1.4 \\
\hline \multicolumn{3}{|l|}{ Education } \\
\hline Primary & 349 & 3.7 \\
\hline Secondary & 2587 & 27.1 \\
\hline Undergraduate & 4966 & 52.0 \\
\hline Postgraduate & 998 & 10.4 \\
\hline Others & 656 & 6.9 \\
\hline \multicolumn{3}{|l|}{ Occupation } \\
\hline Government official & 3043 & 31.5 \\
\hline Worker & 2965 & 30.7 \\
\hline Student & 1644 & 17.0 \\
\hline Others & 930 & 9.6 \\
\hline Business owner & 488 & 5.1 \\
\hline Retired & 310 & 3.2 \\
\hline Unemployed & 281 & 2.9 \\
\hline \multicolumn{3}{|l|}{ Nationality } \\
\hline CIS & 4427 & 47.1 \\
\hline German - Austrian & 1343 & $14 \cdot 3$ \\
\hline English & 345 & $3 \cdot 7$ \\
\hline
\end{tabular}




\begin{tabular}{|c|c|c|}
\hline Variables & $\mathbf{N}$ & $\%$ \\
\hline Dutch & 814 & 8.7 \\
\hline Scandinavian & 809 & 8.6 \\
\hline French & 431 & 4.6 \\
\hline Eastern Europe & 416 & 4.4 \\
\hline Others & 806 & 8.6 \\
\hline \multicolumn{3}{|l|}{ Marital Status } \\
\hline Married & 5134 & 51.8 \\
\hline Single & 4783 & 48.2 \\
\hline \multicolumn{3}{|l|}{ Annual Income } \\
\hline 0-5.999 Euro & 2956 & 34.8 \\
\hline 6.000-11.999 Euro & 1708 & 20.1 \\
\hline 12.000-17.999 Euro & 972 & 11.4 \\
\hline 18.000-23.999 Euro & 697 & 8.2 \\
\hline 24.000-29.999 Euro & 703 & 8.3 \\
\hline$>30.000$ Euro & 1460 & 17.2 \\
\hline \multicolumn{3}{|c|}{ Travel Behaviours Information } \\
\hline \multicolumn{3}{|c|}{ Holiday Organization Mode } \\
\hline Individually & 1497 & 15.1 \\
\hline Package tour & 8406 & $84 \cdot 9$ \\
\hline \multicolumn{3}{|l|}{ Accompanying Person } \\
\hline Travel alone & 1140 & 11.7 \\
\hline Spouse & 1900 & $19 \cdot 5$ \\
\hline Spouse and children & 2707 & 27.7 \\
\hline Friends/relatives & 2393 & $24 \cdot 5$ \\
\hline Others & 1618 & 16.6 \\
\hline \multicolumn{3}{|l|}{ Form of Package Tour } \\
\hline Only room & 616 & 6.2 \\
\hline Bed and breakfast & 351 & 3.5 \\
\hline Half board & 503 & 5.1 \\
\hline Full board & 343 & $3 \cdot 5$ \\
\hline All-inclusive & 8092 & 81.7 \\
\hline \multicolumn{3}{|l|}{ Length of Stay } \\
\hline 1-5 days & 663 & 6.7 \\
\hline 6-10 days & 5940 & 59.9 \\
\hline 11-15 days & 2909 & 29.4 \\
\hline 16-20 days & 198 & 2.0 \\
\hline 21 days and more & 199 & 2.0 \\
\hline
\end{tabular}




\section{Tourist Perceptions of Antalya as a Tourism Destination}

The research explored tourists' expectations of Antalya's attributes. Deriving from a 7 point Likert-type scale for all attributes, the grand mean of attribute-expectation score was 5.33. Accordingly, it was possible to classify attributes with lower and higher expectations. In this context, the grand means could be classified as 'higher expectancy', and the below grand means could be classified as 'lower expectancy'. In other words, local means of transportation, cleanliness, personal safety, cultural and artistic activities, sports activities, conformity to hygienic rules, communication with the local population, reachability of Antalya city, and availability of tourist information were within the lower expectancy group, whereas, accommodation services, cultural values, Turkish cuisine, food and beverage services, shopping opportunities, historic sites, nature, appropriateness for family holidays and hospitality of the local population were within the higher expectancy group. According to Grand means, the highest expectancy aligns to 'appropriateness for family holidays' and the lowest is associated with 'local means of transportation'.

Table 2 Grouping of Tourists According to Their Expectations

\begin{tabular}{|l|c|c|}
\hline & N & $\%$ \\
\hline High Expectancy Group & 3622 & 58.6 \\
\hline Low Expectancy Group & 2564 & 41.4 \\
\hline
\end{tabular}

Classifying sampled tourists as high and low expectancy groups enable evaluation of tourists in terms of their expectations. By using clustering analysis, it is possible to classify groups according to similarities or differences among the variables (Özdamar, 2004; Churchill, 1995). To determine cluster analysis for each tourist in the sample, a total expectancy score was calculated. In finding the total expectancy scores, the replies of tourists according to destination attributes were added together. Finally, the total expectancy scores were used as the criterion to classify tourists. In this context, $\mathrm{K}$ average clustering analysis was used; and it was shown that 3622 tourists were in the high expectancy group and 2564 tourists in the low expectancy group (both being homogeneous tourist groups). Some 58.6 per cent of tourists have high expectations and 4I.4 per cent have low expectations.

In order to define any difference between two groups, in terms of expectancy scores, $t$ tests were completed. The t-test results show that the average expectancy score was I09.45 for the high expectancy group and 80.54 for low expectancy group. The difference between these groups was statistically significant $(\mathrm{p}=\mathrm{O} . \mathrm{OOO})$.

\section{Tourist Satisfaction from Antalya Destination}

The perceptions of tourists sampled, regarding perceived quality attributes of their destination was investigated. For the total attributes, the overall Grand mean was 5.48 . Using the Grand mean it was possible to classify attributes with lower and higher expectations. With this aim, the local means of transportation, cleanliness, shopping opportunities, Turkish cuisine, cultural and artistic activities, sports activities, conformity to hygiene rules, communication with the local population, reachability of Antalya city and availability of tourist information, were attributes with lower satisfaction. Accommodation services, cultural values, food and beverage services, historic sites, nature, appropriateness for family holidays, personal safety and hospitality of the local population had higher satisfaction. Based upon 
Table 3 General Satisfaction

\begin{tabular}{|l|c|c|}
\hline & N & $\%$ \\
\hline Extremely Dissatisfied & 203 & 2.3 \\
\hline Strongly Dissatisfied & 195 & 2.2 \\
\hline Somewhat Dissatisfied & 332 & 3.8 \\
\hline Not Sure & 968 & 11.1 \\
\hline Satisfied & 1805 & 20.6 \\
\hline Somewhat Satisfied & 2293 & 26.2 \\
\hline Extremely Satisfied & 2956 & 33.8 \\
\hline Average & & 5.59 \\
\hline Standard Deviation & & 1.45 \\
\hline
\end{tabular}

the Grand means, the highest satisfaction is 'appropriateness for family holidays' and the lowest 'sports activities' and 'conformity to hygienic rules'.

In this study, the satisfaction levels of sampled tourists from Antalya Region as a tourism destination were calculated based on destination attributes. In addition to this calculation a single overall satisfaction question was asked of respondents' overall satisfaction with Antalya Region. In recent years, despite the fact that tourism researchers addressed the calculation of satisfaction, in terms of qualities, there is widespread belief that there is a difference between general satisfaction and theoretical satisfaction for all attributes (Oliver, I993: 427-428). In other words, tourists with satisfaction of destination attributes, results in them having overall satisfaction with destination (Hsu, 2003: 297).

Based upon the response of single (final) 'overall satisfaction' question, the majority were satisfied with the Antalya Region. Some 20.6 per cent were satisfied, 26.2 per cent somewhat satisfied, and 33.8 per cent extremely satisfied with the destination (Table 3). Overall, 80.6 per cent of tourists were satisfied. Conversely, only 8.3 per cent of tourists were dissatisfied. Similarities can be drawn from the related literature; specifically that there is a relationship between overall satisfaction and theoretical satisfaction across attributes. The correlation coefficient is 0.536 when comparing overall satisfaction and theoretical satisfaction across attributes. This coefficient is statistically significant $(\mathrm{p}=\mathrm{O} . \mathrm{OOO})$ and indicates a moderate and positive relationship.

Table 4 Grouping of Tourists in terms of Satisfaction Levels

\begin{tabular}{|r|c|c|}
\hline & N & $\%$ \\
\hline High Expectancy Group & 3786 & 61.4 \\
\hline Low Expectancy Group & 2376 & 38.6 \\
\hline
\end{tabular}

Classifying sampled tourists as high and low satisfied groups, enables evaluation in terms of their satisfaction. By using cluster analysis, it is possible to categorize groups according to similarities or differences amongst variables. To undertake cluster analysis for each tourist in the sample, a total satisfaction score was calculated. K-average cluster homogeneous tourist groups showed that 3786 tourists in the high-satisfied group and 2376 tourists in low-satisfied group. Some 6I.4 per cent were in the high-satisfied group and 38.6 per cent in low-satisfied group (Table 4). In order to define any difference between the two groups in terms of satisfaction scores, a t-test was conducted. The t-test results indicate that the average satis- 
faction score was III.44 for high satisfaction and 80.04 for low satisfaction. The difference between these two groups was statistically significant $(\mathrm{p}=0.000)$.

\section{The Relationship between Expectation and Satisfaction Levels of Tourists}

As previously discussed, satisfaction levels can be thought of as a function of expectations, related to destination attributes. The relationship between expectation and satisfaction is summarised in Table 5 .

Table 5 The Relationship Between Expectation and Satisfaction Correlation Coefficient

\begin{tabular}{|l|l|c|c|}
\hline \multirow{5}{*}{ Expectation } & \multicolumn{1}{|c|}{ Expectation } & Satisfaction \\
\cline { 2 - 4 } & Pearson Correlation Coefficient & 1 & $0.724^{*}$ \\
\cline { 2 - 4 } & Sig. (2-tailed) & & .000 \\
\cline { 2 - 4 } & $\mathrm{N}$ & 6186 & 5021 \\
\hline \multirow{3}{*}{ Satisfaction } & Pearson Correlation Coefficient & $0.724^{\star}$ & 1 \\
\cline { 2 - 4 } & Significance & .000 & 6162 \\
\cline { 2 - 4 } & $\mathrm{N}$ & 5021 & \\
\hline
\end{tabular}

* Correlation coefficient is significant at $p=0.01$ level

For each tourist in the sample, total expectation and total satisfaction scores were calculated. In addition, in order to find the relationship between expectation and satisfaction variables, correlation analysis was carried out. The result shows a correlation coefficient of 72.4. This coefficient was statistically significant; and it can be concluded that there was a positive and strong relationship between expectation and satisfaction variables. This result also showed that most of the expectations of sampled tourists were met.

In this study, expectation and satisfaction calculations were made for the same destination attributes. An expectation-satisfaction matrix was developed and is shown in Figure I. Based upon the Grand means, tourists' expectations can be divided into two groups, namely lowand high-expectations. Similarly, satisfaction levels of tourists can be grouped as lower- and higher-satisfaction levels. In this context, there will be four different quadrants in the matrix. The quadrant " $\mathrm{A}$ " groups higher-expectation and higher-satisfaction, the quadrant " $\mathrm{B}$ " is lower-expectation and lower-satisfaction, quadrant " $\mathrm{C}$ " is higher-expectation and lower-satisfaction, and the quadrant " $\mathrm{D}$ " indicates lower-expectation and higher-satisfaction. Destination attributes were distributed in the matrix according to their Grand means. For 'expectation', the overall Grand mean was 5.33 and for 'satisfaction', 5.48 is the threshold value.

The distribution of destination attributes according to the expectation and satisfaction matrix is as follows (Figure I):

\section{Quadrant A: Higher expectation and higher satisfaction}

- Appropriateness for Family Holidays

- Food and Beverage Services

- Historic Sites

- Cultural Values

- Nature

- Accommodation Services

- Hospitality of the Local Population 
Quadrant B: Lower expectation and lower satisfaction

- Local Means of Transportation

- Cultural and Artistic Activities

- Communication with the Local Population

- Sports Activities

- Conformity to Hygienic Rules

- Cleanliness

- Availability of Tourist Information

- Reachability of Antalya City

Quadrant C: Higher expectation and lower satisfaction

- Turkish Cuisine

- Shopping Opportunities

Quadrant D: Lower expectation and higher satisfaction

- Personal Safety

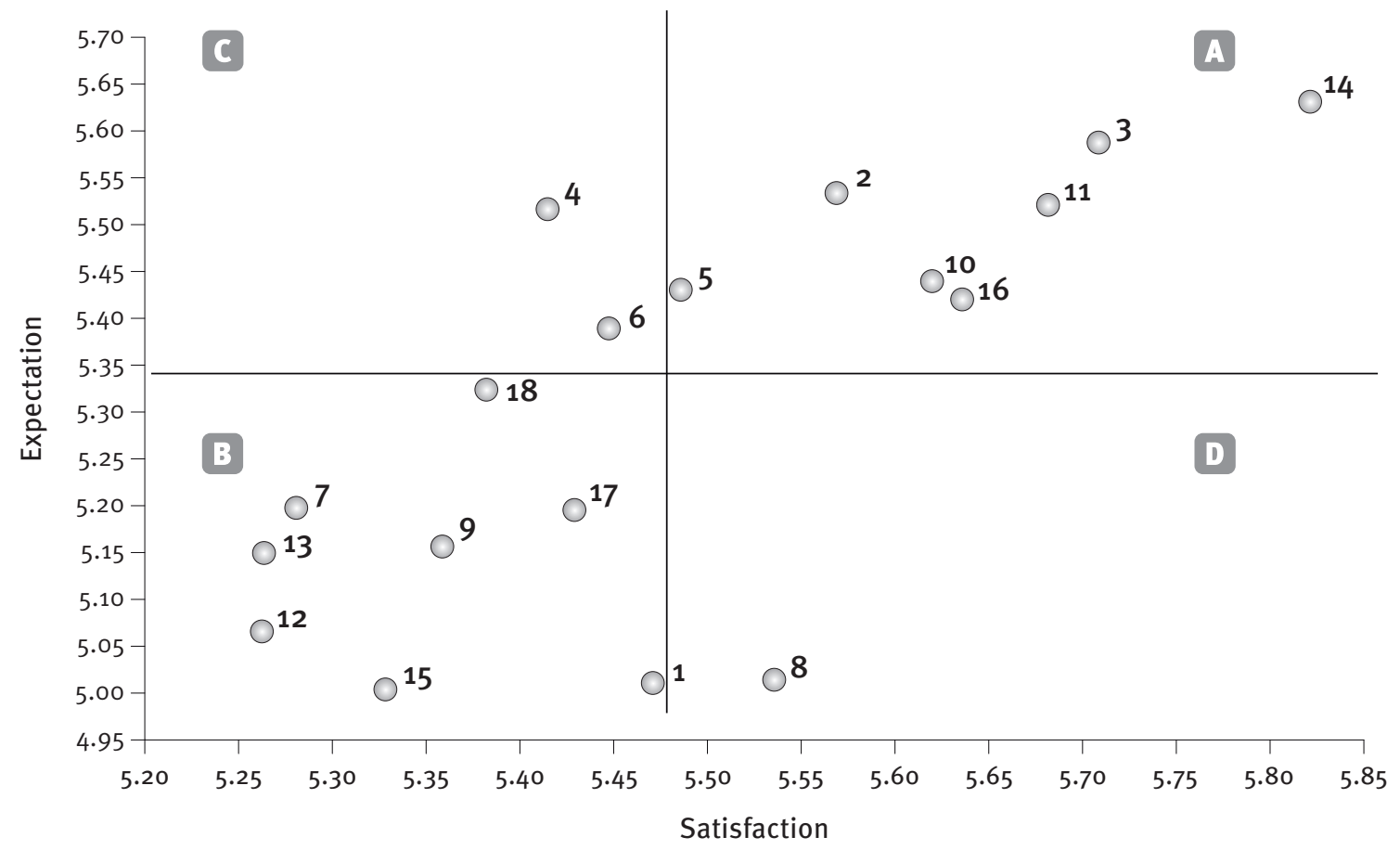

Figure 1 Expectation-Satisfaction Matrix

Key: 1. Local Means of Transportation; 2. Accommodation Services; 3. Hospitality of the Local Population; 4. Turkish Cuisine; 5. Food and Beverage Services; 6. Shopping Opportunities; 7. Cleanliness; 8. Personal Safety; 9. Cultural and Artistic Activities; 10. Historic Sites; 11. Nature; 12 . Sports Activities; 13. Conformity to Hygienic Rules; 14. Appropriateness for Family Holidays; 15. Communication with the Local Population; 16. Cultural Values; 17. Reachability of Antalya City; 18. Availability of Tourist Information 
For the destination attributes within the quadrant "A", it can be argued that tourists had relatively high expectations before their trip that were met by the destination. Accordingly, the destination should keep up with the good work regarding this category of attributes. Attributes that are located in the quadrant " $D$ " exhibited relatively low expectations among tourists before the trip that were exceeded by the destination. Consequently, the destination management should try to analyze whether these attributes are generally important to tourists, because, if they are, these attributes could be used e.g. in promotional strategies to further strengthen the destination's position on the international tourism market. Concerning the attributes in the quadrant "B" tourists had lower expectations which were also met; however, this is because the tourists' satisfaction was also relatively low. Finally, with regard to the attributes which fall into the quadrant " $\mathrm{C}$ ", tourists had relatively high expectations before their trip, however, these were not met by the destination. Since the tourists' satisfaction with these attributes falls significantly below their (high) expectations, the destination management should primarily focus on these attributes in their efforts to improve the overall destination quality.

\section{Conclusions and Recommendations}

Many of the sampled tourists came to Antalya Region with higher expectations, and left the region with higher satisfaction. Similarly, there was a high percentage that has intention to revisit and a willingness to recommend Antalya Region to others. It can be concluded, therefore, that every satisfied tourist, potentially will be revisit the region and will be an ambassador of the region through 'mouth to mouth publicity'. Hence, creating loyal tourists to the region is very important when receiving new tourists.

When expectation and satisfaction levels of sampled tourists were compared, it can be concluded that most of the expectations were met. But despite high expectations of Turkish cuisine and shopping opportunities, the satisfaction levels were low. From this result it can be suggested that Turkish cuisine must be served within a local food and beverage culture; and shopping opportunities must be developed and the quality and range of goods must be improved.

It was seen that the sampled tourists had lower expectations and lower satisfaction levels for local means of transportation, cultural and artistic activities, communication with the local population, sports activities, and conformity to hygienic rules, cleanliness, availability of tourist information and reachability of Antalya city. In a way these attributes can be seen as reliable indicators for improving goods and services and creating /developing an improved image of the Antalya Region. In fact, for all tourism destinations, developing local means of transportation, improving cultural and artistic activities, increasing interaction between tourists and local population, increasing sports activities (especially for tourists), conformity to hygienic rules, giving updated, detailed and correct information and developing infrastructure to improve reachability of tourism destinations are important. In particular, developing local transportation will bring about a valuable enhancement to Antalya Region image. Subsequently, tourists can be advised of hotels wider a field as well as those in the city centre of Antalya.

As a tourism destination, Antalya Region has advantages such as appropriateness for family holidays, food and beverage services, historic sites, cultural values, nature, accommodation services and hospitality of the population. The results drawn from higher-expec- 
tation and higher-satisfaction quadrant of the Expectation-Satisfaction Matrix support these areas of achievement. For future marketing efforts of the Antalya Region, these attributes must be specially mentioned and used in marketing strategies both for short-term and longterm recommendations.

Regarding personal safety, sampled tourists had a low expectation, but had high satisfaction after their holidays in the region. Receiving this positive feedback of the region can be regarded as an important aspect for tourists' safety and welfare. In today's world, feeling safe or having a perception of safety is very important and a key competitive advantage over rival destinations.

The strongest point of this study is the size of the sample, but much more researches must be done again with wider examples and different regions of Turkey. Of course current outcomes of this study can be seen as practical implications for tourism stakeholders and academicians as well. This study can be considered as a useful information and guidance for tourism related decisions. In other words the results are of value for government officials, academicians and tourism professionals.

\section{References}

Abdeldayem M.M., Khanfar M.R (2007). Consumer Expectation and Consumer Satisfaction Measurements: A Case Study from India, The Business Review 8 (2), 303-309.

Churchill G. A. (1995). Marketing Research Methodological Foundations, The Dryden Press, Toronto.

Cronin J.J.,Taylor S.A.(I992). Measuring Service Quality: A Reexamination and Extension, Journal of Marketing, 56, 55-68.

Hu Y., Ritchie J.R.B. (1993). Measuring Destination Attractiveness: A Contextual Approach, Journal of Travel Research 32 (2), 25-34.

Hsu, C.H. (2003). Mature Motor-Coach Travellers' Satisfaction: A Preliminary Step toward Measurement Development, Journal of Hospitality and Tourism Research 20 (IO), I-I9.

Huh, J., Uysal, M., McCleary, K. (2006). Cultural/Heritage Destinations: Tourist Satisfaction and Market Segmentation, Journal of Hospitality and Leisure Marketing I4 (3), 8I-99.

Korzay, M., Alvarez, M. D. (2005). Satisfaction and Dissatisfaction of Japanese Tourists in Turkey, Anatolia, An International Journal of Tourism and Hospitality Research I6(2), I76-I93.

Kozak, M., Bigne, E., Andreau L. (2004). Satisfaction and Destination Loyalty: A Comparison between Non-Repeat and Repeat Tourists, Journal of Quality Assurance in Hospitality and Tourism 5 (I), 43-59.

Kozak, M., Rimmington M. (2000). Tourist Satisfaction with Mallorca, Spain, as an Off Season Holiday Destination, Journal of Travel Research 38 (3), 260-269.

Leiper, N. (1979). The Framework of Tourism: Towards a Definition of Tourism, Tourist and the Tourist Industry, Annals of Tourism Research 6 (4), 390-407.

Oliver, R., (I98I). Measurement and Evaluation of Satisfaction Process in Retail Settings, Journal of Retailing, 57, 25-48

Oliver, R.L.,(I980). A Cognitive Model of the Antecedents and Consequences of Satisfaction Decisions, Journal of Marketing Research I7, 460-469.

Oliver R. L. (1993). Cognitive, Affective, and Attribute Bases of the Satisfaction Response, Journal of Consumer Research, 20, 4I8-43O. 
Özdamar, K. (2004). Statistical Data Analysis with Package Programmes (Multi Variable Analysis) II, Kaan Publishing, Eskişehir. (In Turkish)

Parasuraman A., Zeithaml V.A., Berry L.L. (I988). SERVOUAL: A Multiple Item Scale for Measuring Customer Perceptions of Service Quality, Journal of Retailing 64 (I), I2-37

Pizam A., Neumann Y., Reichel, A. (1978). Dimensions of Tourist Satisfaction with a Destination Area, Annals of Tourism Research 5 (3), 3I4-322.

Stevens, Blair, F. (I992). Price Value Perceptions of Travellers. Journal of Travel Research 3I (Fall), 44-48.

Teas, R.K. (1994). Expectations as a Comparison Standard in Measuring Service Quality: An Assessment of a Reassessment, Journal of Marketing 58 (I), I32-I39.

Uysal, M.(1998). The Determinants of Tourism Demand: A Theoretical Perspective, The Economic of the Tourist Industry, Routledge, London.

Yoon Y., Uysal, M. (2005). An Examination of the Effects of Motivation and Satisfaction on Destination Loyalty: A Structural Model, Tourism Management 26(I), 45-56. 